\title{
Effects of Chamber Perforations, Inlet and Outlet Pipe Diameter Variations on Transmission Loss Characteristics of a Muffler Using Comsol Multiphysics
}

\author{
Randy Amuaku ${ }^{1, *}$, Eric Amoah Asante ${ }^{1}$, Ampaw Edward ${ }^{1}$, George Bright Gyamfi ${ }^{2}$ \\ ${ }^{1}$ Mechanical Engineering Department, Faculty of Engineering, Koforidua Technical University, Koforidua, Ghana \\ ${ }^{2}$ Automotive Engineering Department, Faculty of Engineering, Koforidua Technical University, Koforidua, Ghana
}

Email address:

amuaku.randy@ktu.edu.gh (R. Amuaku)

${ }^{*}$ Corresponding author

To cite this article:

Randy Amuaku, Eric Amoah Asante, Ampaw Edward, George Bright Gyamfi. Effects of Chamber Perforations, Inlet and Outlet Pipe Diameter Variations on Transmission Loss Characteristics of a Muffler Using Comsol Multiphysics. Advances in Applied Sciences. Vol. 4, No. 6, 2019, pp. 104-109. doi: 10.11648/j.aas.20190406.11

Received: October 5, 2019; Accepted: November 13, 2019; Published: December 10, 2019

\begin{abstract}
Confronted with noise disturbance during transmission of vehicle exhaust air, several mufflers have been designed to control the noise and improve the transmission characteristics. In order to optimize the noise control and attenuation quality, the internal geometry, inlet and outlet pipe diameters of a designed muffler were varied and the performance evaluated using finite element method (FEM). Furthermore, $2 \mathrm{~mm}$ diameter equal circular perforations were introduced in the resonator chamber to verify the effect on the transmission loss characteristics. The results show that the performance of the muffler with inlet pipe diameter variation is significantly better $(68 \mathrm{~dB})$ than the standard muffler $(55 \mathrm{~dB})$ in controlling and reducing acoustic wave propagation within the same frequency range of $(200 \sim 580 \mathrm{~Hz})$. The performance improved further to $70 \mathrm{~dB}$ by the introduction of circular perforations in resonator chamber. However, with the variation in the outlet diameter increase the performance of the muffler was $55 \mathrm{~dB}$ but within a higher frequency range of $220 \sim 680 \mathrm{~Hz}$ which is not reliable for acoustic wave propagation control. The average transmission loss performance of the designed mufflers were 48.62, 47.77, 39.01 and $37.77 \mathrm{~dB}$ for the resonator chamber perforation, inlet pipe diameter increase, outlet pipe diameter increase and standard muffler respectively. Therefore, the designed muffler with resonator chamber perforations is the best for optimal acoustic wave control.
\end{abstract}

Keywords: Finite Element Method (FEM), Transmission Loss Characteristics (TL), Resonator Chamber Perforations, Boundary Element Method (BEM)

\section{Introduction}

Mufflers have been widely used in vehicle exhaust systems for years due to their broadband characteristics at mid to high frequency. Noise, generated by automotive engine combustion has effects on hearing [1]. Furthermore, high impulse engine combustion noise has effects on human organs leading to hearing loss [2]. The frequency range for engineering interest covers more than the range which is audible to the human ear. The normal hearing frequency range is within $20 \mathrm{HZ}$ to $20 \mathrm{HZ}$. [3]. However, noise from vehicle engines is generally above the maximum frequency of $20 \mathrm{HZ}$. As a result, mufflers are normally used to reduce exhaust noise from engine combustion. Mufflers are mainly reactive type mufflers and absorptive type mufflers. Reactive mufflers reduce the noise by using the destructive interference. Sound reflections occur when there is a change in geometry or area discontinuity and pipe perforations in the muffler. Absorptive type mufflers use absorptive materials to convert the energy of sound waves into heat. The absorptive materials are mostly lined in the muffler chambers to minimize back pressure. Highly efficient design and its performance per application have encouraged engineers to develop various acoustic elements within mufflers like variations in chamber diameters, the introduction of rigid baffles, perforation of baffles, the different density of absorptive liners and pipes with different diameter perforations and so on. Transmission loss is a ratio of sound 
power incident (in decibel) at the entry to that which is transmitted by the muffler [4]. Several numerical methods for calculating the Transmission Loss characteristics in an exhaust muffler system have been investigated using Comsol software and Actran software. Although plane wave models are available for the prediction of the sound attenuation in mufflers at low frequency, multidimensional analytical techniques and numerical methods are required for higher frequencies and propagation at higher order modes [6]. As a result, numerical techniques have found favor for modeling complex geometries and application of arbitrary boundary conditions [7]. Among the numerical methods, the Finite Element Method (FEM) is widely used and relevant literature can be found regarding the acoustic modeling of mufflers [6]. For instance, Parlar, Z., et al., [8] Analyzed the Transmission loss reductions in a silencer analytically using NASTRAN software with comparative experimental results.

Furthermore, Kulkarni and Ingle [9] evaluated and calculated harmonic pressure waves in a silencer of an internal combustion engine exhaust system to reduce the Transmission Loss characteristics using Comsol software. Similarly, Potente calculated the principles of design concepts and benefits of mufflers using numerical analysis [10]. In another study Berger., et.al used Fluent environment to investigate the reaction of a silencer in reducing transmission loss [11]. Shu et. al [12], studied the effects of several muffler configurations on transmission loss characteristics and provided guidelines for muffler system optimization [13]. Similarly Goldsborough and Van blarigan provided strategies for muffler optimization [14]. $\mathrm{Yu}$ et al presented a theoretical description of the overall transmission loss for a cascade-connected multiple subchambers used in achieving a desired attenuation performance [15]. Jena and Panigrahi [16] considered two special cases of reactive silencers and investigated their acoustic performance using numerical and experimental techniques. Based on the literature reviewed, it is now clear that the geometrical parameters of the designed muffler have significant effect on the performance optimization. Therefore, this study seeks to, (1) improve the performance characteristics of a muffler by varying parts of the geometry. (2) investigate the geometrical variation effect on the acoustic wave transmission loss characteristics by using Comsol Multiphysics software. (3) evaluate varied geometrical parameter combination effect on transmission loss characteristics.

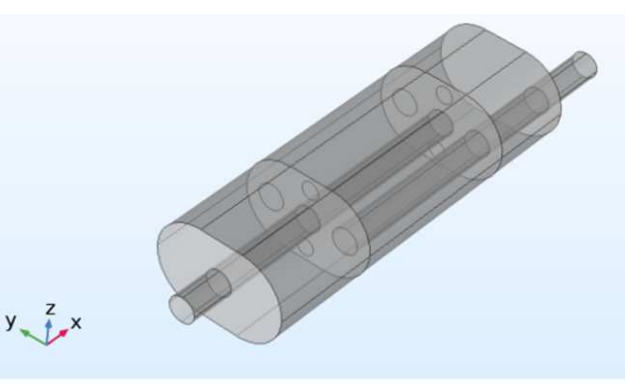

(b) Internal view of the proposed muffler

(a) Outer view of the proposed muffler

Figure 1. Geometries of the muffler considered.

\section{Materials and Methods}

\subsection{Theoretical Model Analysis}

A commercial pressure acoustic model package, Comsol Multiphysics software was used to calculate the transmission loss characteristics of the muffler considered under a frequency domain study. The equation applied is a modified Helmholtz equation for the acoustic pressure $p$ [17],

$$
\nabla *\left(-\frac{\nabla p}{\rho}\right)-\frac{\omega^{2} p}{c^{2} \rho}=0
$$

Where, $\rho$ rho is the density, $\omega$ is the angular frequency, $c$ is the speed of sound. The considered muffler model was calculated in the low-frequency range under reactive damping is consideration instead of resistive damping. Three different boundary conditions were applied to the considered muffler model. A sound hard (wall) boundary condition was applied to the outer walls of the muffler, the plates dividing the resonator chambers and the walls of the inlet and outlet pipes.

$$
\left(-\frac{\nabla p}{\rho}\right) * n=0
$$

At the inlet boundary a combination of an incoming and an outgoing plane waves were assumed,

$$
\left(-\frac{\nabla p}{\rho}\right) * n=\frac{i \omega}{\rho c} p-\frac{2 i \omega}{\rho c} p_{O}
$$

Where, $p_{O}$ denotes the applied outer pressure and $i$ the imaginary element. At the outlet boundary, an outgoing plane wave was applied,

$$
\left(-\frac{\nabla p}{\rho}\right) * n=\frac{i \omega}{\rho c} p
$$

The acoustic effect at the inlet and outlet end of the considered muffler was calculated using the equations 5 and 6 given below;

Acoustic effect at the Inlet 


$$
p_{i n}=\int_{\partial \Omega} \frac{p_{O}^{2}}{2 \rho c} d A
$$

Acoustic effect at the Outlet

$$
p_{\text {out }}=\int_{\partial \Omega} \frac{\left|p_{c}\right|^{2}}{2 \rho c} d A
$$

Where, $p_{\text {in }}$ is Acoustic effect at the Inlet and $p_{\text {out }}$ is Acoustic effect at the Outlet. Transmission Loss is a ratio of sound power incident (in decibel) at the entry to that which is transmitted by the muffler [4]. Transmission loss in the designed muffler;

$$
T L=10 \log \left(\frac{p_{\text {in }}}{p_{\text {out }}}\right)
$$

The geometrical parameters used for the study are shown in Table 1.

Table 1. Parameters and physical properties for Muffler Simulation.

\begin{tabular}{lll}
\hline Parameters & Value & Description \\
\hline$p_{O}$ & $1[\mathrm{~Pa}]$ & Amplitude of incoming pressure wave \\
$d_{1}$ & $3[\mathrm{~mm}]$ & Diameter of inlet pipe \\
$d_{2}$ & $3[\mathrm{~mm}]$ & Diameter of outlet pipe \\
$h_{1}$ & $750[\mathrm{~mm}]$ & Length of muffler \\
$w_{1}$ & $300[\mathrm{~mm}]$ & Width of muffler \\
$r h o_{1}$ & $1.225 \mathrm{~kg} / \mathrm{m}^{3}$ & Density of Air \\
$s p d_{1}$ & $343[\mathrm{~m} / \mathrm{s}]$ & Speed of sound in Air \\
$M m_{1}$ & $0.02897[\mathrm{~kg} / \mathrm{mol}]$ & Mean molar mass of Air \\
\hline
\end{tabular}

\subsection{Parameter Computations and Simulation}

To verify the aim of the research in relation to the effects of parameter variations on the muffler's transmission loss characteristics, the inlet and outlet diameters were varied. Also, circular perforations of equal diameters were introduced into the resonator chambers of the muffler as shown in Table 2. The pressure acoustic module of Comsol Multiphysics software 5.4 was used to solve the transmission characteristics of the muffler model [18]. The physics module in the software is coupled with other physics interface modules to solve the transmission characteristic problems. To calculate the transmission loss characteristics, it was necessary to define a boundary condition at the input and output ends of the muffler model. Three boundary conditions in the pressure acoustics module were applied to the inlet, outlet and resonator chamber. A hard wall boundary condition was applied to the outer layers of the muffler and given a velocity of zero. At the inlet of the muffler, a combination of incoming and outgoing plane waves was applied to specifically define the entry and exit outlets of the acoustic wave transmission in the muffler [19]. At the outlet end of the muffler an outgoing plane wave radiation condition was applied.

Table 2. Varied geometrical parameters.

\begin{tabular}{lll}
\hline Parameter Name & Value & Description \\
\hline$d_{1}$ & $3.8[\mathrm{~mm}]$ & Diameter of inlet pipe \\
$d_{2}$ & $5[\mathrm{~mm}]$ & Diameter of outlet pipe \\
$h_{1}$ & $750[\mathrm{~mm}]$ & Height of muffler \\
$w_{1}$ & $300[\mathrm{~mm}]$ & Width of muffler \\
$d_{c p}$ & $2[\mathrm{~mm}]$ & Diameter of circular perforation \\
\hline
\end{tabular}

\section{Results and Discussions}

\subsection{Parameter Computations and Simulation Analysis}

The absolute pressure and sound pressure level distribution in the muffler are indicated by the various colour contours presented in Figures 2 and 3 below. The colour contours show regions of high and low sound and absolute pressure levels. In Figure 2, the red colored zones represent high absolute pressure levels whiles the blue colored zones represent low absolute pressure levels.

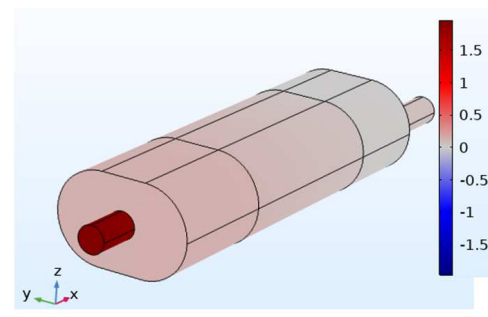

(a) Absolute Pressure level at Frequency of $100 \mathrm{~Hz}$

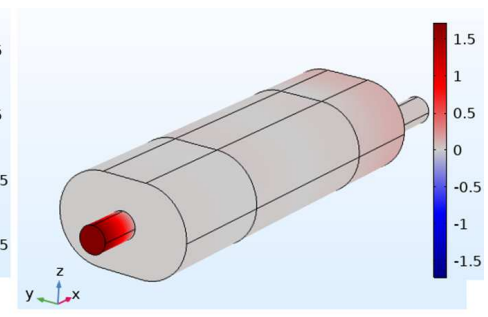

(b) Absolute Pressure level at Frequency of 500Hz
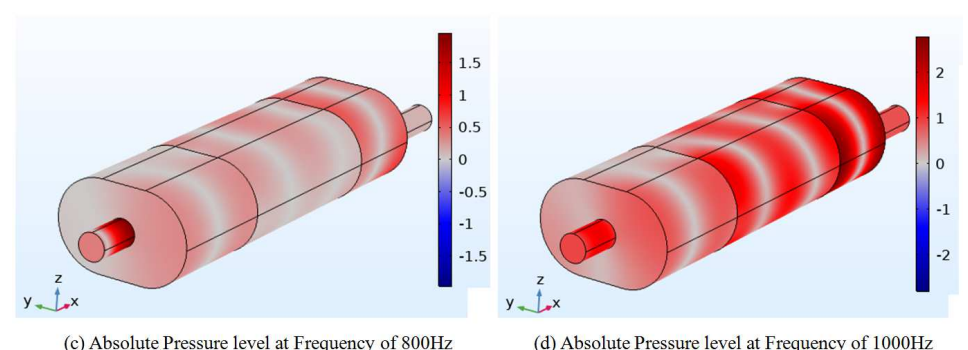

(d) Absolute Pressure level at Frequency of $1000 \mathrm{~Hz}$

Figure 2. Absolute Pressure on the muffler at Frequencies $100 \mathrm{~Hz}, 500 \mathrm{~Hz}, 800 \mathrm{~Hz}$ and $1000 \mathrm{~Hz}$. 
However, the grey colored zones represent regions with medium absolute pressure levels. Increase in frequency causes an increase in absolute pressure levels on the muffler. In Figure 3 below, the red colored zones represent regions of high sound pressure levels on the muffler whiles the green and yellow colored zones represent regions of medium sound pressure levels. The blue colored zones however, represent regions of low sound pressure levels.

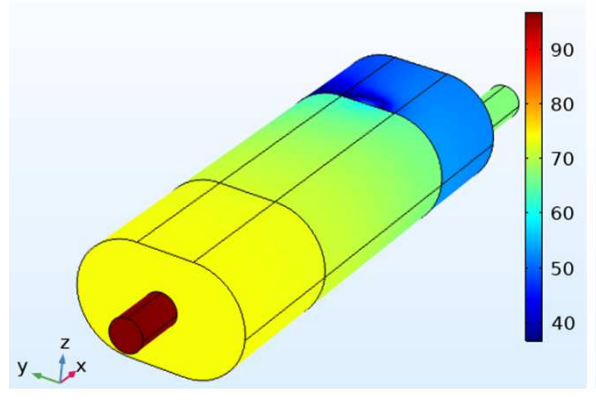

(a) Sound Pressure level at a Frequency of $100 \mathrm{~Hz}$

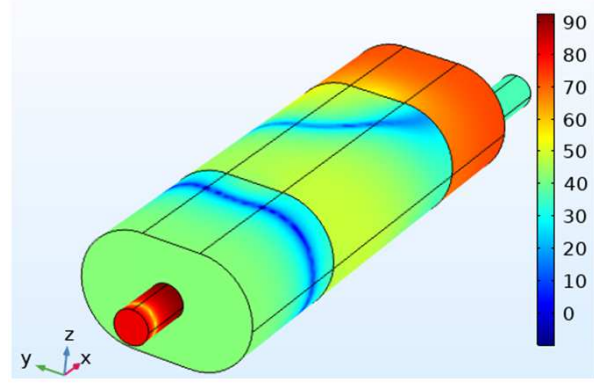

(c) Sound Pressure level at a Frequency of $800 \mathrm{~Hz}$

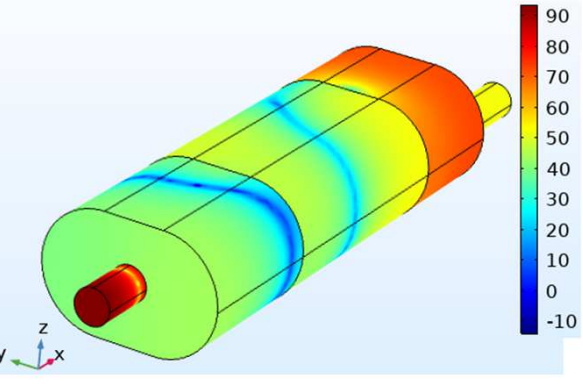

(b) Sound Pressure level at a Frequency of $500 \mathrm{~Hz}$

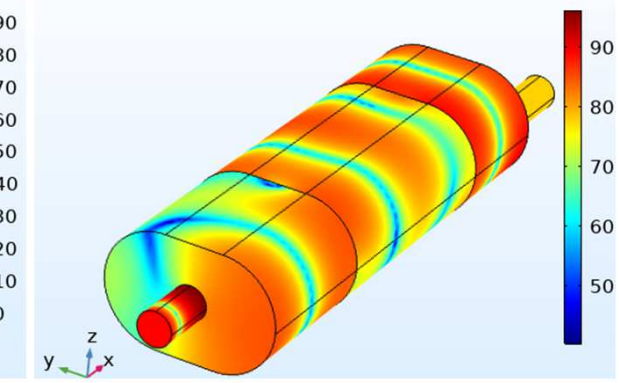

(d) Sound Pressure level at a Frequency of $1000 \mathrm{~Hz}$

Figure 3. Sound Pressure level on the muffler at Frequencies $100 \mathrm{~Hz}, 500 \mathrm{~Hz}, 800 \mathrm{~Hz}$ and $1000 \mathrm{~Hz}$.

\subsection{Comsol Multiphysics Simulation Analysis}

In the simulation of the muffler, certain parameter computations were considered. In the first simulation condition, a standard muffler without resonator chamber perforations and parameter variation was studied. Subsequently, three perforations of the same diameter were made in the resonator chambers connecting the inlet and outlet ends of the muffler and analyzed. In the third parameter computation, the diameters of the inlet and outlet ends of the muffler was varied and analyzed. Theoretically, the transmission loss characteristics will increase with the increase in the ratio of the resonator chamber to both inlet and outlet pipe cross-sectional area. [20]. Therefore, using equation 7 , the transmission loss characteristics was calculated and the simulation results for the muffler without any variation of individual parameters presented in Figure 4. A broad transmission loss characteristic spikes with a peak of $60 d B$ was obtained within low frequency range of $155 \sim 550 \mathrm{~Hz}$.

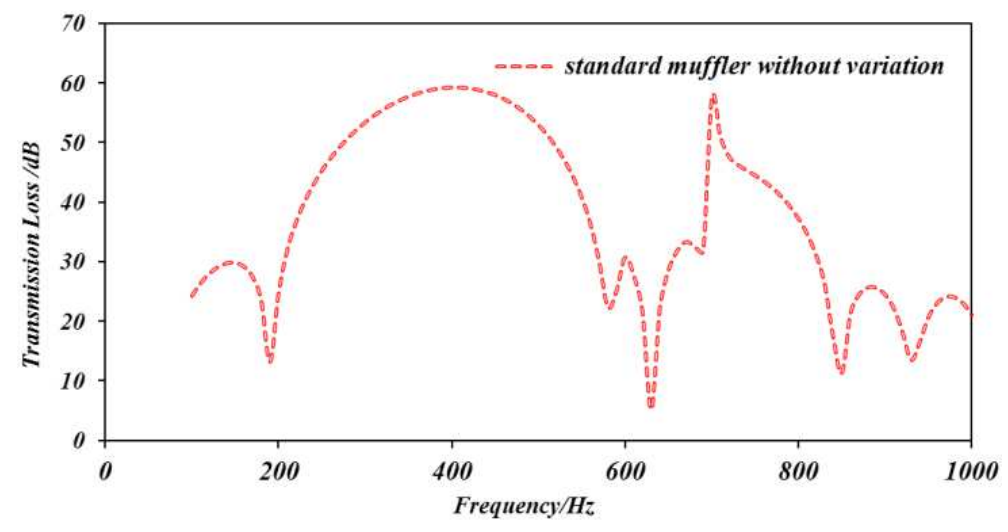

Figure 4. Transmission Loss Characteristics of the standard muffler without any parameter variation.

The parameters of the standard muffler design had no perforations in the resonator chamber and also has equal inlet and outlet diameters. Different muffler designs concept was investigated and the results compared to the standard muffler.
The simulation results of three varied muffler parameters and the standard muffler design are presented in Figure 5. The standard muffler had good broad transmission loss characteristic spike of $60 d B$ within a low-frequency range of 
$200 \sim 580 \mathrm{~Hz}$ and $63 \mathrm{~dB}$ at a frequency of $700 \mathrm{~Hz}$. The muffler design concept with circular perforation had the highest transmission loss characteristics of $70 \mathrm{~dB}$ within a low-frequency range of $198 \sim 600 \mathrm{~Hz}$ and $65 \mathrm{~dB}$ at a frequency of $700 \mathrm{~Hz}$. The muffler with varied input pipe diameter had a transmission loss characteristics of $68 \mathrm{~dB}$ within a low-frequency range of $200 \sim 580 \mathrm{~Hz}$. However, the performance of the muffler with varied outlet diameter (transmission loss characteristic of $58 \mathrm{~dB}$ and $38 \mathrm{~dB}$ at frequency range of $240 \sim 680 \mathrm{~Hz}$ and $680 \sim 820 \mathrm{~Hz}$ respectively) was lower than the standard muffler (transmission loss characteristics of $60 d B$ and $68 d B$ at a frequency $198 \sim 580 \mathrm{~Hz}$ and $630 \sim 850 \mathrm{~Hz}$ respectively). It is clear from the analysis that an increase in the input pipe diameter leads an increase in the transmission loss characteristics [21]. Subsequently, introducing circular perforations into the resonator chambers at equally spaced angles improves the transmission loss characteristics by reducing the back pressure [22]. With the introduction of three circular perforations of $2 \mathrm{~mm}$ diameter each the transmission loss was improved by more than $28 \%$ over the standard muffler. Subsequently, the transmission loss characteristics was improved by more than $25 \%$ over the standard muffler due to $27 \%$ increase in the inlet pipe diameter. Therefore, perforation in the resonator chamber has a better effect on the transmission loss than variation in pipe diameter.

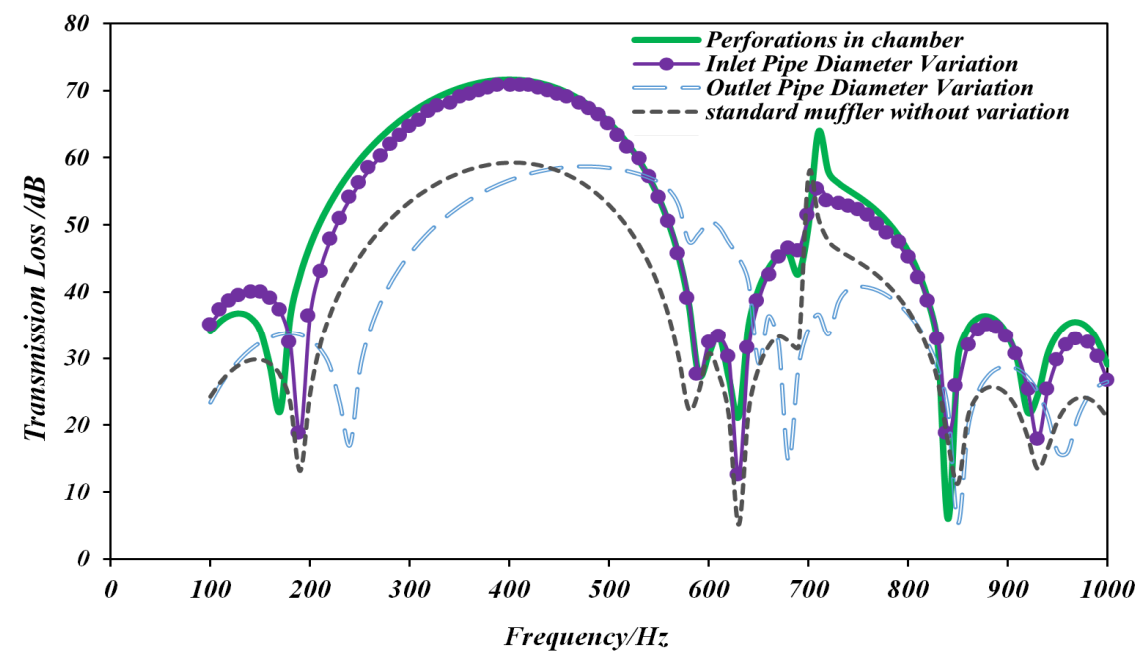

Figure 5. Transmission Loss Characteristics of varied Parameters of the muffler.

\section{Conclusion}

In this paper, the effects of muffler chamber perforations, inlet and outlet pipe diameter variations on transmission loss characteristics has being put forward using comsol multiphysics software. It is clear from the analysis that a direct correlation exists between input diameter increase and an increase in transmission loss characteristics. Introducing circular perforations into the resonator chambers at equally spaced angles improved the transmission loss characteristics due to reduction in the back pressure. With the introduction of three circular perforations of $2 \mathrm{~mm}$ diameter each the transmission loss was improved by more than $28 \%$ over the standard muffler. The transmission loss characteristics was improved by more than $25 \%$ over the standard muffler as a result of the $27 \%$ increase in the inlet pipe diameter. Therefore, it can be concluded that perforation in the resonator chamber has a better effect on the transmission loss characteristics than variation in pipe diameter. The authors recommend that the muffler should be developed and the performance evaluated experimentally. Furthermore, analysis should be carried out on the resonator chamber perforations using a combination of different hole sizes at different angle orientations. Therefore, it can be concluded that perforation in the resonator chamber has a better effect on the transmission loss characteristics than variation in pipe diameter.

\section{Acknowledgements}

The authors wish to acknowledge that this research work was founded by the Faculty of Engineering and the Academic Research Department of Koforidua Technical University.

\section{References}

[1] Žiaran, S. and O. Chlebo, Noise control transmission methods of the combustion engine by means of reduction of the vibration. Archives of Acoustics, 2016. 41 (2): p. 277-284.

[2] Hong, O., et al., Understanding and preventing noise-induced hearing loss. Dis Mon, 2013. 59 (4): p. 110-118.

[3] Lee, J., et al., Behavioral hearing thresholds between 0.125 and $20 \mathrm{kHz}$ using depth-compensated ear simulator calibration. Ear and hearing, 2012. 33 (3): p. 315.

[4] Chen, Y. and D. Xu. Optimization of Noise Reduction Performance for the Muffler in a Heavy Vehicle. in IOP Conference Series: Materials Science and Engineering. 2018. IOP Publishing. 
[5] Sánchez-Orgaz, E., et al., Numerical mode matching for sound propagation in silencers with granular material. Journal of Computational and Applied Mathematics, 2019. 350: p. 233246.

[6] Brebbia, C. A., J. C. F. Telles, and L. C. Wrobel, Boundary element techniques: theory and applications in engineering. 2012: Springer Science \& Business Media.

[7] Parlar, Z., et al., Acoustic and flow field analysis of a perforated muffler design. World Academy of Science, Engineering and Technology, 2013. 7: p. 03-27.

[8] Kulkarni, M. V. and R. B. Ingle, Attenuation analysis and acoustic pressure levels for double expansion chamber reactive muffler: Part 2. Noise \& Vibration Worldwide, 2018. 49 (6): p. 241-245.

[9] Potente, D. General design principles for an automotive muffler. in Proceedings of ACOUSTICS. 2005.

[10] Berger, E., Methods of measuring the attenuation of hearing protection devices. The Journal of the Acoustical Society of America, 1986. 79 (6): p. 1655-1687.

[11] Shu, G., et al., Configuration optimization of the segmented modules in an exhaust-based thermoelectric generator for engine waste heat recovery. Energy, 2018. 160: p. 612-624.

[12] Goldsborough, S. S. and P. Van Blarigan, Optimizing the scavenging system for a two-stroke cycle, free piston engine for high efficiency and low emissions: A computational approach. SAE transactions, 2003: p. 1-20.
[13] Yu, X., et al., Sub-chamber optimization for silencer design. Journal of sound and vibration, 2015. 351: p. 57-67.

[14] Yu, X., Modeling, analysis, and optimization of complex vibroacoustic systems with micro-perforates. 2016, The Hong Kong Polytechnic University.

[15] Jena, D. and S. Panigrahi, Numerically estimating acoustic transmission loss of a reactive muffler with and without mean flow. Measurement, 2017. 109: p. 168-186.

[16] Dupré, M., et al., Layer potential approach for fast eigenvalue characterization of the Helmholtz equation with mixed boundary conditions. Computational and Applied Mathematics, 2018. 37 (4): p. 4675-4685.

[17] Andersen, P. R., Modelling of acoustic viscothermal losses using the Boundary Element Method: From method to optimization. 2018.

[18] Puthuparampil, J., Aeroacoustic Noise Prediction and Acoustic Optimization of Mufflers. 2018.

[19] El Malki, M. and A. Khettabi. Application of the interface response theory to a periodical expansion chambers. in AIP Conference Proceedings. 2019. AIP Publishing.

[20] Bhadke, P. and K. J. I. J. M. C. E. Mahajan, no. March, Effect of Change in Diameter on Muffler Transmission loss using COMSOL. 2017: p. 2278-1684.

[21] Elsayed, A., et al., Investigation of baffle configuration effect on the performance of exhaust mufflers. 2017. 10: p. 86-94. 